\title{
Quo vadis Endocrine
}

\author{
Andrea Giustina
}

Published online: 6 March 2011

(C) Springer Science+Business Media, LLC 2011

This is my first Editorial as Editor-in-Chief of Endocrine and, first of all, I would like to welcome all the old and new readers of the journal to what I hope will be, for most of them, a common house for staying in touch with the latest advancements in basic and clinical endocrine research.

Previous Editor-in-Chief and founder of the journal, Dr. Michael Conn, has done a wonderful job of achieving a strong reputation for Endocrine in the scientific community. When Springer, the new and very well-known publisher of the journal, first contacted me about the opportunity to become the new Editor-in-Chief, my feelings were mixed. I felt honored and pleased but, at the same time, conscious of accepting a big challenge. Now the decision has been made, and you probably do not want to hear more about private things, such as my family being a little nervous about my having extra work on nights and weekends. Instead, I guess you are much more interested in knowing what we already did for the journal and along what lines we intend to move toward the future of Endocrine.

First of all, I want to share with the readers what my concept of being an Editor-in-Chief is. I served on the Editorial Boards of many international endocrine journals, and I learned a great deal from many marvelous editors. They taught me that running a journal is not a one-man show. It is a team effort in which Associate Editors, Editorial Board, reviewers, and publisher all play very important roles. A good Editor-in-Chief is the one who limits to a minimum the mistakes and bias that the whole peer-reviewing process unavoidably bears per se. The

\footnotetext{
A. Giustina $(\square)$

Department of Medical and Surgical Sciences,

University of Brescia, Brescia, Italy

e-mail: Endocrine_eic@libero.it
}

ultimate goal, in fact, is always to publish the best science possible; of course, as a result of the space constraints that all the journals have, there are choices to be made that are often close calls. Moreover, a good Editor-in-Chief should have in mind a strategic plan to develop the journal and, in particular, be able to understand the evolving needs of the readership. In fact, any scientific journal should be published not in order to satisfy the egos of the editors or the publishers, but with the precise objective of making a useful contribution to the progress of science and to the exchange of notions and cross-talk among researchers.

At this point, how do we put this theory into practice? In other words (you will excuse my Latin use, which is a tribute to my origins as an Italian)-quo vadis Endocrine?

My first step as an Editor-in-Chief was, as a consequence of the principles that I alluded above, to put together an effective editorial team. I will have three Associate Editors (Carmine Gazzaruso, Gherardo Mazziotti, and Giovanni Tulipano) who will work closely with me in running the journal, a role facilitated by their also being close to me geographically. They are three relatively young scientists, highly committed with strong scientific backgrounds [1-3] and very good experience in handling research manuscripts. I know from direct previous experience in cooperation with them that they will do fantastic work and soon become a steady reference for all of you. Moreover, with their help, we have put together a superb Editorial Board possessing incredible endocrine and metabolic skills. Just take a look at the list of members to immediately understand that this Board will soon become one of the biggest strengths of the journal. These great experts, who are also great men and women, were selected to represent the whole endocrine world in terms of both countries and areas of interest (their expertise covers all the main fields of endocrinology, diabetes, and metabolism). 
On a personal level, I want to acknowledge the motivation, friendship, and commitment that these colleagues have displayed in accepting with enthusiasm our invitation to join us in this challenge. We expect from this excellent Board much great advice and many contributions that will certainly benefit the journal. With their help, we will also try to choose the best reviewers possible and guarantee the fastest turn-around of submitted manuscripts in an effort to assure our authors of a quick first decision.

All of the manuscripts will be handled via the Editorial Manager system, which is a very user-friendly program that is historically well run by Springer. Springer, the publisher of Endocrine, is known around the globe for its commitment to scientific publications and for being a very strong organization. With such a publisher, the journal is highly likely to be in very good shape to deal with all of the contemporary challenges of scientific publishing. The Editorial Office will be run by Springer, but I will also be constantly available at my e-mail address for help in solving, as quickly as possible, any problems that authors may face with their submissions.

Last but not least, what are the innovations that readers might expect in the immediate future, and how do we plan to meet their expectations? One could say that there are so many very authoritative journals specifically dedicated to the areas of endocrine disease, diabetes, and metabolic diseases including bone that there is very little space for innovation. On the contrary, I think that in this respect, endocrinology offers a unique scenario for scientific publishing. The cross-talk between glands [4], between diverse endocrine and metabolic environments, or with other non-endocrine systems such as the heart $[5,6]$; our fastdeveloping comprehension of the pathophysiological mechanisms of endocrine disease, often involving different systems [7]; and, finally, the incredibly rapid advent of new molecules [8,9] or strategies [10] for the treatment of endocrine and metabolic diseases all make the world of endocrine publishing in general more exciting than ever. This, coupled with our ability to convey new information in developing areas of endocrinology-such as the endocrinology of aging [11, 12]-and the selection of the most promising work will make all the difference in the success of this journal.

As you will see in the journal's new Instructions for Authors, we have articulated new possibilities for contributing to the journal. We still think that updated and timely Reviews are very useful to the readers, and we will put all of our effort into soliciting the best authors to write for us. However, unsolicited Review proposals will also be carefully considered. We have also introduced Mini-Reviews, which will allow for even more rapid and concise contributions on selected hot topics. Original Articles will deal with basic, translational, and clinical research on all of the main topics in the various fields of endocrinology and metabolism. Preliminary data that do not sustain a full paper can now been submitted in the form of a Research Letter, for which an even faster turnaround time relative to Original Articles will be put in place. We think that most readers like to see expert views on current, particularly (but not necessarily) clinical, controversies. Our role will be to solicit contributions, such as Editorials and Perspectives, from authoritative experts with different points of view. To complete the re-dedication of Endocrine as a forum, Letters to the Editor in the form of comments on published articles or brief descriptions of particularly interesting observations will also be accepted.

In conclusion, the editorial and publishing teams of Endocrine will put all of their efforts into providing good service to the endocrine and metabolic community around the world. We are and will always be open to any kind of contribution which may improve our quality, for which I will ultimately be responsible. You will judge whether the above-described directions are the right ones for the journal, and if the answer to the quo vadis question will result in the complete satisfaction of our readers.

\section{References}

1. C. Gazzaruso, S.B. Solerte, A. Pujia, A. Coppola, M. Vezzosi, F. Salvucci, C. Valenti, A. Giustina, A. Garzaniti, Erectile dysfunction as a predictor of cardiovascular events and death in diabetic patients with angiographically proven asymptomatic coronary artery disease: a potential protective role for statins and 5-phosphodiesterase inhibitors. J. Am. Coll. Cardiol. 51, 2040-2044 (2008)

2. G. Mazziotti, E. Canalis, A. Giustina, Drug-induced osteoporosis: mechanisms and clinical implications. Am. J. Med. 123, 877-884 (2010)

3. G. Tulipano, R. Stumm, M. Pfeiffer, H.J. Kreienkamp, V. Höllt, S. Schulz, Differential beta-arrest in trafficking and endosomal sorting of somatostatin receptor subtypes. J. Biol. Chem. 279, 21374-21382 (2004)

4. A. Giustina, W.B. Wehrenberg, Influence of thyroid hormones on the regulation of growth hormone secretion. Eur. J. Endocrinol. 133, 646-653 (1995)

5. G. Mazziotti, A. Bianchi, S. Bonadonna, V. Cimino, I. Patelli, A. Fusco, A. Pontecorvi, L. De Marinis, A. Giustina, Prevalence of vertebral fractures in men with acromegaly. J. Clin. Endocrinol. Metab. 93, 4649-4655 (2008)

6. A. Giustina, R. Lorusso, V. Borghetti, G. Bugari, V. Misitano, O. Alfieri, Impaired spontaneous growth hormone secretion in severe dilated cardiomyopathy. Am. Heart J. 131, 620-622 (1996)

7. L.G. Danescu, S. Levy, J. Levy, Vitamin D and diabetes mellitus. Endocrine 35, 11-17 (2009)

8. E. Canalis, A. Giustina, J.P. Bilezikian, Mechanisms of anabolic therapies for osteoporosis. N. Engl. J. Med. 357, 905-916 (2007)

9. I. Donangelo, S. Melmed, Treatment of acromegaly: future. Endocrine 28, 123-128 (2005)

10. A. Giustina, S. Bonadonna, G. Bugari, A. Colao, R. Cozzi, S. Cannavo, L. de Marinis, E. Degli Uberti, F. Bogazzi, 
G. Mazziotti, F. Minuto, M. Montini, E. Ghigo, High-dose intramuscular octreotide in patients with acromegaly inadequately controlled on conventional somatostatin analogue therapy: a randomised controlled trial. Eur. J. Endocrinol. 161, 331-338 (2009)

11. A. Giustina, M. Licini, A.R. Bussi, A. Girelli, G. Pizzocolo, M. Schettino, A. Negro-Vilar, Effects of sex and age on the growth hormone response to galanin in healthy human subjects. J. Clin. Endocrinol. Metab. 76, 1369-1372 (1993)

12. S.S. Harris, B. Dawson-Hughes, No effect of bicarbonate treatment on insulin sensitivity and glucose control in non-diabetic older adults. Endocrine 38, 221-226 (2010) 